\title{
Validity of Shunt Pumping Test as a Screening Modality for Shunt Block: An Experimental Study
}

\author{
Manish Sharma ${ }^{1}$ Suman Kumar ${ }^{2}$ \\ ${ }^{1}$ Department of Neurosurgery, Command Hospital NC), Udhampur, \\ Jammu and Kashmir, India \\ 2Department of Hematology, Army Hospital (R\&R), Delhi Cantonment, \\ New Delhi, India \\ Indian J Neurosurg 2019;8:35-41
}

Address for correspondence Manish Sharma, MCh, Department of Neurosurgery, Command Hospital (NC), Udhampur 182101, Jammu and Kashmir, India (e-mail: manish_dwl@yahoo.com).

\begin{abstract}
Purpose To ascertain the validity and efficacy of shunt compression test in evaluating a blocked shunt.

Methods An experimental model was created using a Chhabra shunt, and 25 physicians with 1 to 3 years of experience in neurosurgery were asked to assess the block in the model where artificial blocks were created.

Results The sensitivity of test to detect any block was found to be 0.76 ( $95 \%$ confidence interval [Cl]: 0.7-0.81), specificity was $0.71(0.59-0.81)$, positive likelihood ratio 2.59 (1.81-3.7), and negative likelihood ratio 0.34 (026-0.45). Odds ratio for proximal block was 4.33 (95\% Cl: 2.01-8.92), and for distal block, it was 10.63 (95\% Cl: 10.6322.32). Furthermore, predictive probability for shunt block was maximum when both the ends were considered to be blocked by the investigator and the test was found to

Keywords

- hydrocephalous

- manual chamber compression test

- ventriculoperitoneal shunt

- blocked shunt be poor in predicting a patent shunt.

Conclusion This is not a very reliable screening test to detect presence of a shunt block. Predicted probability for shunt block was maximum when both the ends were considered to be blocked by the investigator. This study results are not in conformity with the previously held belief that delayed refilling of chamber would clearly aid the diagnosis of proximal end block. It is strongly felt that a deliberate training of shunt compression test would aid a better diagnostic ability.
\end{abstract}

\section{Introduction}

Cerebrospinal fluid (CSF) diversion by placement of a shunt is commonly used to treat hydrocephalous. One of the most common complications of this procedure is shunt block, when the CSF flow through the shunt gets blocked and the patient becomes symptomatic with features of raised intracranial pressure (ICP) in the form of altered mentation, headache, vomiting, and visual disturbances. To aid the diagnosis of a shunt block, numerous invasive and noninvasive tests are used. Chamber compression test that can be done bedside is also done. No definite knowledge about its ability to diagnose a blocked shunt is known. In this study, the authors created an experimental model to evaluate the diagnostic limitations of chamber compression test.
DOI https://doi.org/

10.1055/s-0040-1708572

ISSN 2277-954X.

\section{Material and Methods}

Experimental model: An experimental model was created using a Chhabra shunt and a skull ( - Fig 1a, b). The shunt chamber was fixed just behind the left mastoid bone, which matches the anatomical location of chamber in a patient with left-sided shunt. The proximal and distal ends were dipped in a vessel filled with water and placed at a height of 15 and $10 \mathrm{~cm}$, respectively, to replicate intracranial and intra-abdominal pressure gradients. The shunt chamber was covered with a thick noncompressible cotton cloth to replicate presence of skin as close to the real patient.

There are four possible scenarios of shunt block.

1. Scenario PB: Proximal end blocked

2. Scenario DB: Distal end blocked

(C2020 Neurological Surgeons'

Society of India
License terms

() (1) $\Theta \circledast$ 


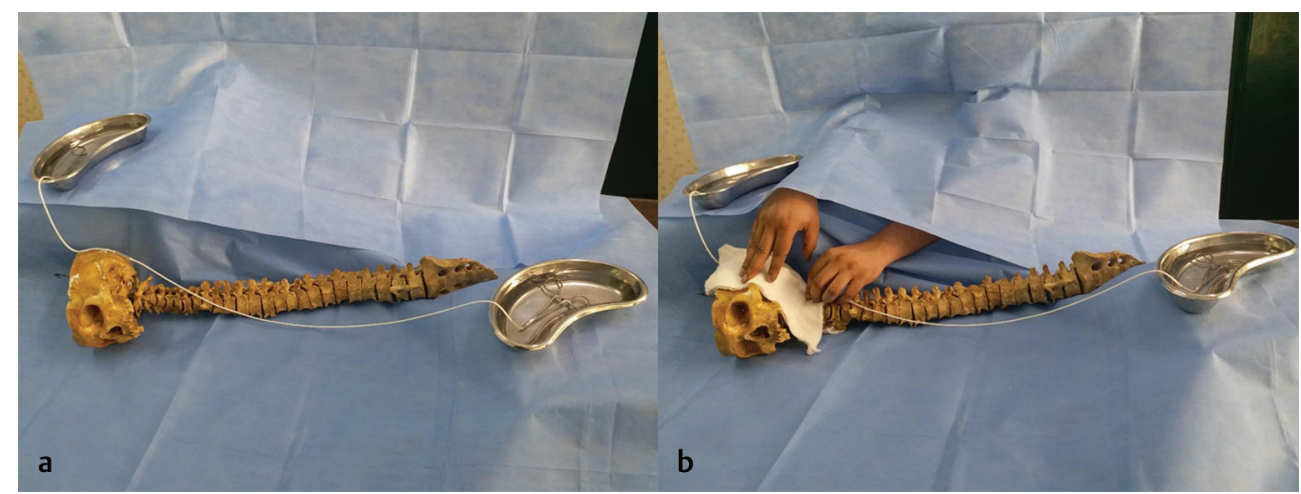

Fig. 1 (a) Setup of model: Shunt chamber of Chhabra shunt fixed just behind the left mastoid. Proximal and distal ends kept elevated to simulate a normal intracranial pressure and intra-abdominal pressure, respectively. (b) Setup of model with investigator: Investigator is blinded and has free access to the shunt chamber.

3. Scenario BB: Both ends blocked

\section{Scenario BO: Both ends open}

An experimentally similar situation was created in this study by using an artery forceps to block the respective end of shunt tubing.

Model setup: Twenty-five physicians (henceforth called investigator) with 1 to 3 years of experience in handling neurosurgical patients were asked to participate. The investigators were trained in general surgery and had medical experience varying from 3 to 6 years. The first author (M.S.) of this study (henceforth called the moderator) was in-charge of producing an artificial block using the artery forceps. A screen was placed between the investigator and the study model so that he could not see the shunt tube or the block. Both the hands were permitted through the screen so that the investigator could support the head as per his habit before compressing the chamber to assess patency. No time restriction was placed.

Conduct of study: Each investigator was given 3 attempts of each possible scenario making a total of 12 attempts per investigator. The investigator and the moderator were blinded to each other by the screen. The scenarios were offered to investigators in a random order, and answers were recorded.

\section{Assessment}

All 300 responses were analyzed. The investigator had four options to be chosen after examining the shunt for block.

1. Proximal end blocked (PB)

2. Distal end blocked (DB)

3. Both ends blocked (BB)

4. Both ends open (BO)

The clinically relevant query for the model was to detect presence of a block irrespective of its side. Investigator's responses were analyzed for their ability to detect presence or absence of any side block (AB).

\section{Statistical Analysis}

The statistical analysis was done by using R3.2.1 R Foundation for Statistical Computing). A logistic regression model, with investigator's response in form of proximal and distal block as predictive variables and presence of any side block as outcome, was devised. ROC (receiver operating characteristic) curve was made out of the logistic regression model (-Fig. 2). This was used to calculate sensitivity, specificity, positive and negative likelihood ratio, and positive and negative predictive values along with their $95 \%$ confidence intervals $(\mathrm{CI})$. Odds ratios were calculated for investigator's response as PB and DB out of the model. Predictive probabilities along with $95 \% \mathrm{Cl}$ of occurrence of $\mathrm{AB}$ for each of the four responses were calculated. The measure of inter-rater concordance is inversely proportional to the heterogeneity of responses between different investigators for the same scenario. Concordance was measured as proportion of all pairwise measurements, with score of 1 if the pairwise measurements were different or 0 if they were same. Lower scores meant higher reliability; $95 \% \mathrm{CI}$ of the concordance index was calculated by bootstrapping method.

\section{Results and Observations}

There were four possible scenarios and four possible responses for each scenario. Overall results obtained and the answers given are depicted in $\mathbf{- T a b l e} \mathbf{1}(\boldsymbol{-}$ Fig. $\mathbf{3})$. Presence of distal block was the most common answer. The scenario of proximal block (PB) in isolation was missed the most as not having any block. Distal block alone was picked up as having some block on maximum number of occasions. In addition, the following significant observations were made:

(a) Both sides open (BO) was correctly identified $71 \%$ times.

(b) BO was never wrongly identified as BB.

(c) Distal block was correctly identified in 47 out of maximum 75 times.

(d) Distal block is the most commonly identified block, and it was felt to be present in $45 \%$ of cases in which some kind of block was present.

(e) Scenario of PB was detected as BO on a significant number of times.

Any block $(A B)$ : $A B$, which clubbed $P B, D B$, and $B B$ as one, was compared with scenario of no block (BO). Total 171 blocks of any kind (PB, DB, BB) were detected 


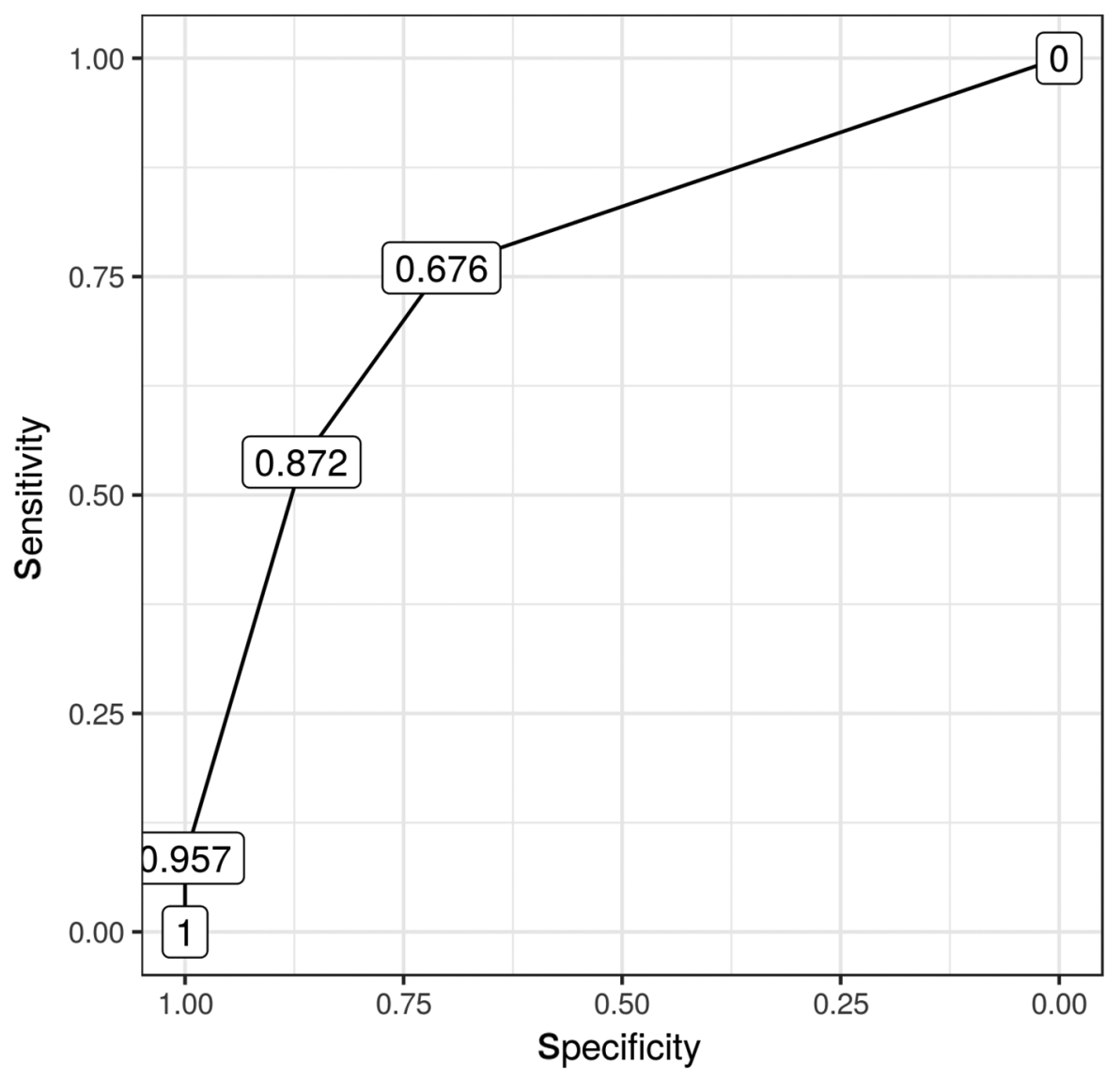

The figures in boxes depict the probability of Any Block as predicted by the model as cut off to discriminate between block and no block

Fig. 2 Receiver operating characteristic curve: AUC of ROC curve is 0.676 and best cutoff is 0.676 . Sensitivity/specificity/LR and predictive values were calculated for the best cutoff.

Table 1 Overall results obtained in all four scenarios

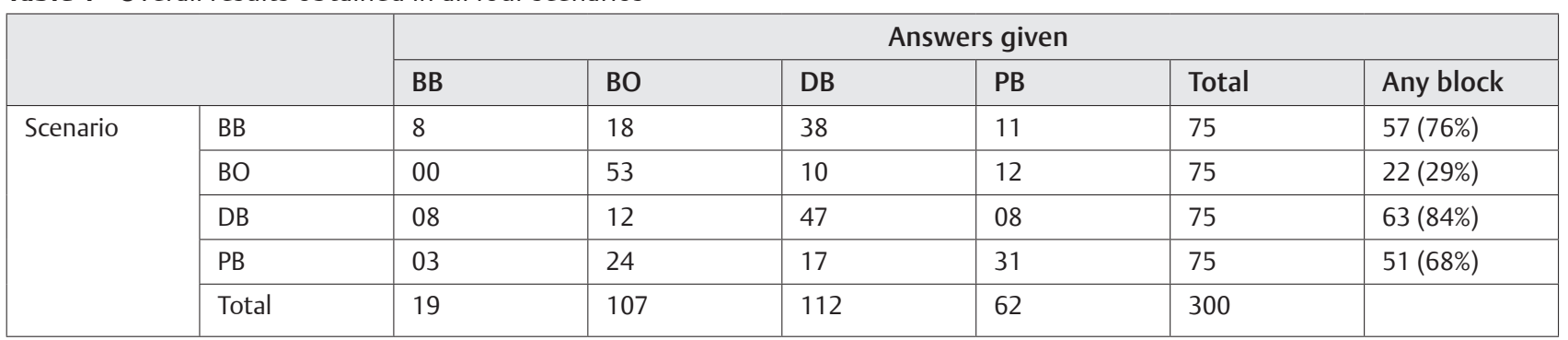

Abbreviations: BB, both ends blocked; BO, both ends open; DB, distal end blocked; PB, proximal end blocked.

correctly to have a block out of a maximum of 225 , and 53 scenarios with no blocks were correctly identified to have no blocks out of a maximum of 75 (-Table 2, -Fig. 4). The following observations were made:

(a) In scenario of a block of any kind, $76 \%$ of times it was detected as a blocked shunt.

(b) When there was no block, it was correctly detected as a functional shunt $71 \%$ of times.

(c) Statistical analysis of these data revealed manual compression of chamber to have a sensitivity of $0.76(0.7-0.81)$ and specificity of 0.71 (0.59-0.81), positive likelihood ratio of 2.59 (1.81-3.7), and negative likelihood ratio of 0.34 (026-0.45) (-Table 3).

(d) Odds ratio for proximal block was found to be 4.33 (95\% CI: 2.01-8.92) implying that when the investigator says that $\mathrm{PB}$ is present, the chance that there is any block is 4.33 times when he says that there is no block. Odds ratio for distal block was 10.63 (95\% CI: 10.63-22.32) (-Table 4).

(e) Predicted probability for any block, when the investigator found both ends blocked, was 0.98 (95\% CI: 0.95-0.99). It was 0.91 (95\% CI: $0.85-0.95)$ for $\mathrm{DB}$ and 0.81 (95\% CI: $0.70-0.89$ ) for PB. Predictive ability was found to be least 


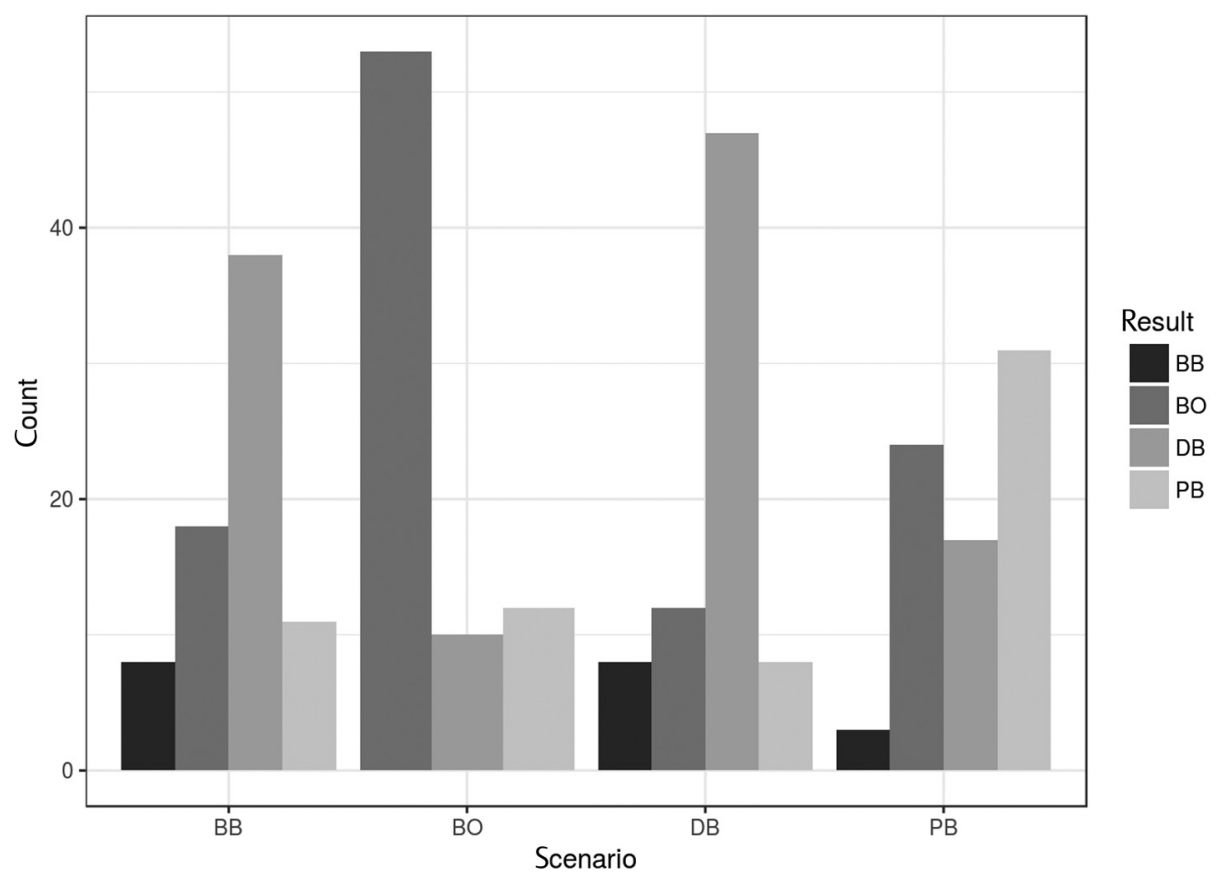

Fig. 3 Overall concordance: Each scenario evaluated has been marked on horizontal x-axis. Detailed response to each scenario as to how it was interpreted has been depicted on vertical y-axis. BB, both ends blocked; BO, both ends open; DB, distal end blocked; PB proximal end blocked.

Table 2 Assessment of AB scenario

\begin{tabular}{|l|l|l|l|l|}
\hline \multicolumn{2}{|c|}{} & \multicolumn{3}{c|}{ Answer given } \\
\cline { 2 - 5 } \multicolumn{2}{c|}{} & Block + & No block & Total \\
\hline \multirow{3}{*}{ Scenario } & AB (PB+DB+BB) & 171 & 54 & 225 \\
\cline { 2 - 5 } & No block (both open) & 22 & 53 & 75 \\
\cline { 2 - 5 } & Total & 193 & 107 & 300 \\
\hline
\end{tabular}

Abbreviations: $\mathrm{AB}$, any block; $\mathrm{BB}$, both ends blocked; $\mathrm{BO}$, both ends open; $\mathrm{DB}$, distal end blocked; PB, proximal end blocked.

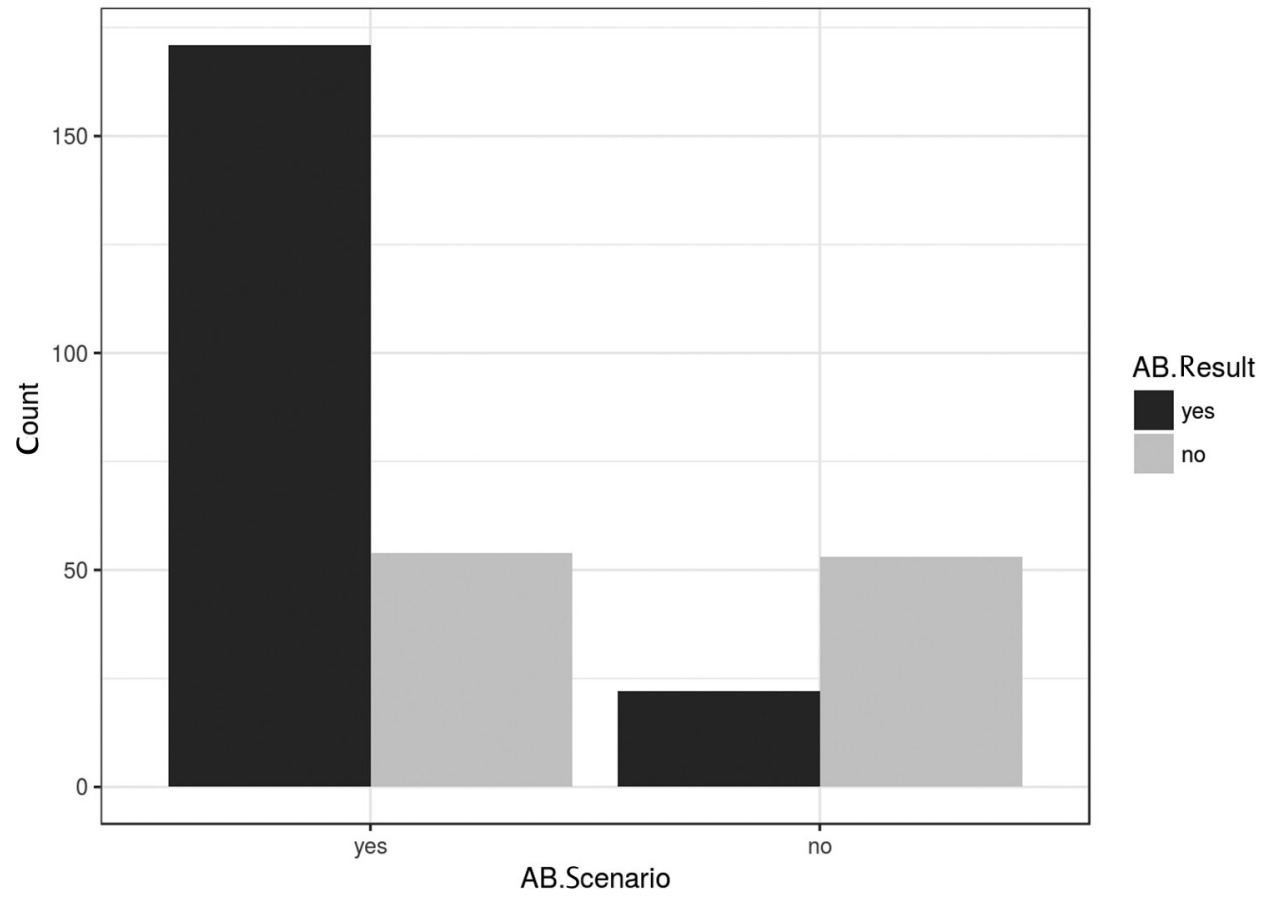

Fig. 4 Any block $(A B)$ versus both open: Any block scenario that clubbed PB, DB, and BB was compared with scenario when no block was present (BO). Correct or incorrect identification of each scenario has been depicted. 
Table 3 Predictive values of experimental model

\begin{tabular}{|l|l|l|l|l|l|l|}
\hline & Sensitivity & Specificity & $\begin{array}{l}\text { Positive } \\
\text { likelihood } \\
\text { ratio }\end{array}$ & $\begin{array}{l}\text { Negative } \\
\text { likelihood } \\
\text { ratio }\end{array}$ & $\begin{array}{l}\text { Positive } \\
\text { predictive } \\
\text { value }\end{array}$ & $\begin{array}{l}\text { Negative } \\
\text { likelihood } \\
\text { value }\end{array}$ \\
\hline Point estimate & 0.76 & 0.71 & 2.59 & 0.34 & 0.89 & 0.50 \\
\hline $\mathrm{Cl}(95 \%)$ & $(0.7-0.81)$ & $(0.59-0.81)$ & $(1.81-3.71)$ & $(0.26-0.45)$ & $(0.83-0.93)$ & $0.40-0.59$ \\
\hline
\end{tabular}

Abbreviation: $\mathrm{Cl}$, confidence interval.

Table 4 Odds ratio

\begin{tabular}{|l|l|l|}
\hline & Odds ratio for any block & $\mathrm{Cl}(\mathbf{9 5 \% )}$ \\
\hline Proximal block prediction & 4.33 & $2.10-8.92$ \\
\hline Distal block prediction & 10.63 & $5.06-22.32$ \\
\hline
\end{tabular}

Abbreviation: $\mathrm{Cl}$, confidence interval.
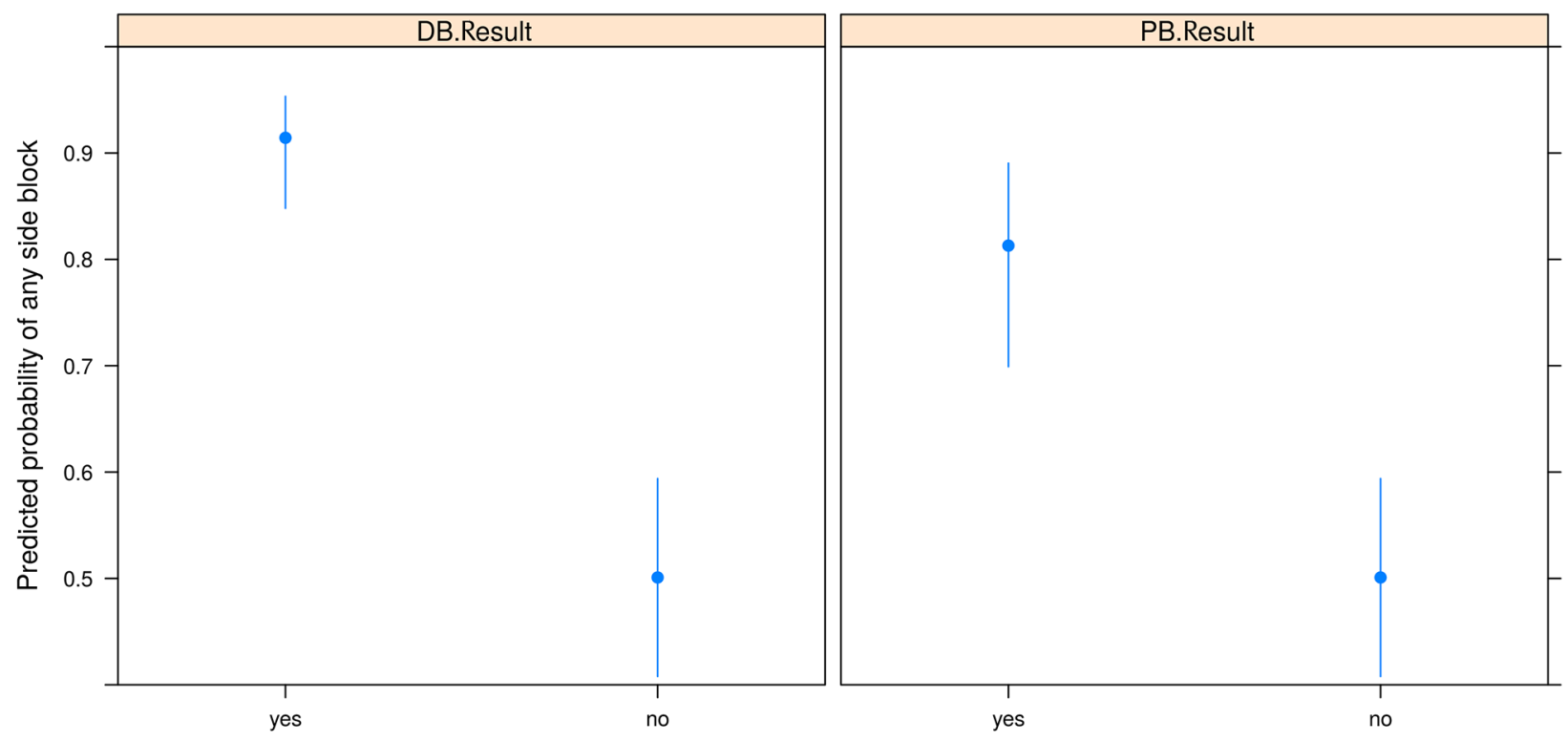

Fig. 5 Predictive ability of responses: There are four possible responses to each scenario. Predictive ability of each response for the presence of any block was calculated. In case of BO scenario, predictive probability to detect a functional shunt has been calculated. DB, distal end blocked; PB proximal end blocked.

Table 5 Predictive ability of responses

\begin{tabular}{|l|l|l|l|l|}
\hline & Both block & Distal block & Proximal block & Both open \\
\hline Point estimate & 0.98 & 0.91 & 0.81 & 0.50 \\
\hline $\mathrm{Cl}(95 \%)$ & $(0.98-0.99)$ & $(0.84-0.95)$ & $(0.70-0.89)$ & $(0.41-0.59)$ \\
\hline
\end{tabular}

Abbreviation: $\mathrm{Cl}$, confidence interval.

for both ends open and was found to be 0.50 (95\% CI: 0.41-0.59) (-Fig. 5, - Table 5).

(f) Inter-rater concordance was best for DB scenario and worst for PB scenario (-Fig. 6, - Table 6).

\section{Discussion}

CSF shunt remains the mainstay of treatment for hydrocephalous. Despite the simplicity of procedure and frequency of this procedure, complications are far too common. Shunt block is one of the most common complications and may cause the patient to repeatedly visit the hospital. Rekate ${ }^{1}$ in their study found the annual incidence of shunt block to be approximately $5 \%$. Sainte-Rose et al, ${ }^{2}$ over a 12 -year period, found occurrence of $56 \%$ shunt blocks in a cohort of 1,217 patients. Lazareff and colleagues ${ }^{3}$ found a prevalence of $44 \%$ of shunt block in 244 patients when followed for a 6-year period. Peacock and Currer $^{4}$ have reported an incidence of shunt block of $20 \%$ in the first year post shunt. Barnes et $\mathrm{al}^{5}$ in 2002 found an incidence of shunt block of $28 \%$ over a follow-up of 10 years. 


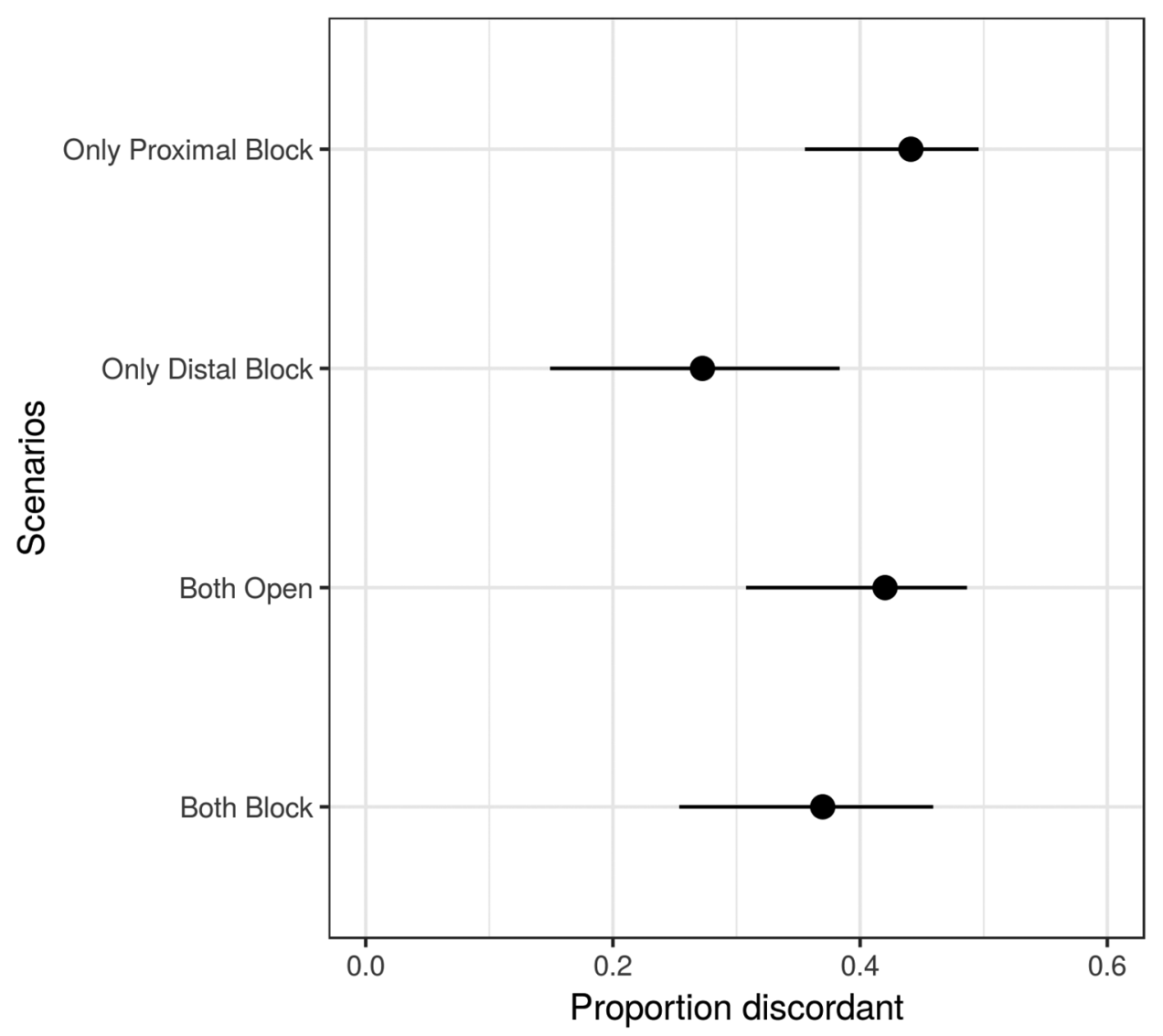

Point is the sample specific discordant index. Line ranges from $95 \%$ lower and upper confidence limits of discordant index calculated by bootstrapping

Fig. 6 Inter-rater concordance: To detect inter-rater variability, heterogeneity of responses was measured. It can be seen that concordance is best for DB and worst for PB.

Table 6 Inter-rater concordance

\begin{tabular}{|l|l|l|}
\hline Scenario & Point score & $\mathrm{Cl}$ \\
\hline BB & 0.37 & $0.25-0.46$ \\
\hline BO & 0.42 & $0.31-0.49$ \\
\hline DB & 0.27 & $0.15-0.37$ \\
\hline PB & 0.44 & $0.36-0.50$ \\
\hline
\end{tabular}

Abbreviations: BB, both ends blocked; $\mathrm{BO}$, both ends open; $\mathrm{Cl}$, confidence interval; DB, distal end blocked; PB, proximal end blocked.

A shunt can get blocked at its proximal end by the brain parenchyma, arachnoid granulations, etc. Its distal end can get blocked by omentum or peritoneal adhesions. Its tubing can get disconnected or kinked leading to a block. At present, there are no definitive means to diagnose presence or absence of shunt block. Numerous invasive and noninvasive methods have been attempted to provide a guide to shunt functioning. Watkins et $\mathrm{al}^{6}$ concluded that direct referral by the parents was more accurate than either referral by any general practitioner or from any other hospital in patients having a blocked shunt. Clinically a shunt block presents with cardinal features of drowsiness, headache, and vomitings. The predictive value of drowsiness has been found to be best with odds ratio of $10(0.69-10.7){ }^{5}$ In the same study, headache has been found to have odds ratio of
1.5 (0.27-10.9) and vomiting 0.9 (0.25-3.65). A plain noncontrast computed tomographic (NCCT) scan of the head is commonly used to evaluate any back pressure changes in the form of dilated ventricles or periventricular ooze. Radionuclide imaging has been used to detect the flow of shunt, and its efficacy has been evaluated in conjunction with NCCT of the head. ${ }^{7-9}$ NCCT of the head has been reported to have a sensitivity of $77.8 \%$ and specificity of $66.7 \%$. Shuntogram has been found to have sensitivity of $92.6 \%$ and specificity of $59.5 \%$. Sood et $\mathrm{al}^{10}$ in their study have recommended using a shunt site reservoir. They placed a subgaleal reservoir next to the shunt and connected it with a ventricular catheter. Pressure measurements of reservoir tap were used to predict shunt malfunction, and they reported $100 \%$ accuracy of diagnosis. Furthermore, reservoir tapping was used to therapeutically decompress the chamber in cases with shunt block. It is difficult to perform these tests as a routine, especially in cases of recurrent visits with suspicion of shunt blockage. Shunt pumping has often been considered as one such test that can be and is often performed at bedside as a first screening test, and slow refilling of reservoir has occasionally been suggested to indicate a proximal block. A classic shunt consists of a ventricular catheter, a chamber with a unidirectional flow valve, and a distal tube that is tunneled subcutaneously and ends in the peritoneal cavity, pleura, or internal jugular vein (IJV) as the 
case may be. Piatt ${ }^{11}$ has previously recommended that interval shunt pumping has poor sensitivity and specificity to be of any diagnostic significance. In their study, Piatt found a sensitivity of 0.50 and a specificity of 0.64 for interval shunt pumping test. Manual compression test works on a premise that the chamber will be incompressible if there is a distal block, and if there is a proximal block, refilling of chamber will either not occur or will be delayed. The compliance of distal tube can be a confounding factor in cases of distal block.

In this study, the authors have created an experimental model and tried to test the validity of bedside shunt compression test. The validity of this study results depends on the model replicating the in situ shunt. A shunt assembly fixed over a skull replicates the hardware as in a patient. The proximal and distal ends that lie in the ventricle and abdominal cavity, respectively, constitute the second variable that could confound the study results. Normal intracranial and intra-abdominal pressures are approximately 7 to 15 and 2 to $5 \mathrm{~cm}$ of water, respectively. ${ }^{8,12,13}$ In this model, water column height of $15 \mathrm{~cm}$ at cranial end and $5 \mathrm{~cm}$ at abdominal end was used to simulate a patient situation. A patient who is exerting or a crying child would have a higher intra-abdominal pressure for the duration of exertion or crying. This dynamic factor has not been taken into account in this study. Any persistent rise in intra-abdominal pressure uniformly or location of shunt in a cyst would also cause a rise in the pressure gradient of distal end and would lead to a shunt block situation.

The sensitivity of the test to detect a blocked shunt was found to be 0.76 and specificity 0.71 . Positive likelihood ratio was 2.59 , and negative likelihood ratio was 0.34 (-Table 3). Although it is better than what was found by Piatt, it is not significant enough for the test to be considered an effective one. Odds ratio of proximal block to predict presence of any block was found to be 4.33 (2.1-8.92), and for distal block, it was 10.63 (5.06-22.31) (-Table 4). Possibility of any block is highest when the investigator feels that both ends are blocked with predictive probability of $0.98(0.95-0.99)$. It is worst to predict a functional shunt with predictive probability of only $0.50(0.41-0.59)$ (-Table 5). Inter-rater concordance was also analyzed, and it was found to be best for DB scenario and worst for PB scenario. This variability in inter-rater concordance makes the authors feel that there is a scope for regular practice and training for this test to further improve the ability of investigators to correctly predict the block and that it is a matter of further study.

\section{Conclusion}

Shunt compression test is a bedside test and more often than not is likely to be the first screening test to be used. It has moderate capability to detect a shunt block. It is most reliable to diagnose a shunt block if both ends are felt by the investigator to be blocked. Distal block has a higher predictive probability than proximal block. Inter-rater variability suggests that there is a scope of training for this test. Regular practice to develop a feel for response of shunt chamber to a block or its absence is likely to improve the performance of investigator and remains subject of further investigation. It is strongly felt that there is a need as well as scope for this test to be developed as a screening test if it is regularly performed and the operators are trained to perform this test.

\section{Funding}

No funding has been obtained from any source for this study.

\section{Disclosures}

There are no disclosures and there are no conflicts of interests involved.

\section{Contributions}

Dr. Manish Sharma contributed to the conceptualization, data collection, manuscript writing. Dr. Suman Kumar contributed to the statistical analysis.

\section{Conflicts of Interest}

There are no conflicts of interest.

\section{References}

1 Rekate HL. Shunt revision: complications and their prevention. Pediatr Neurosurg 1991-1992-92;17(3):155-162

2 Sainte-Rose C, Piatt JH, Renier D, et al. Mechanical complications in shunts. Pediatr Neurosurg 1991-1992;17(1):2-9

3 Lazareff JA, Peacock W, Holly L. Ver Halen J, Wong A, Olmstead C. Multiple shunt failures: an analysis of relevant factors. Childs Nerv Syst 1998;14(6):271-275

4 Peacock WJ, Currer TH. Hydrocephalus in childhood. A study of 440 cases. S Afr Med J 1984;66(9):323-324

5 Barnes NP, Jones SJ, Hayward RD, Harkness WJ, Thompson D. Ventriculoperitoneal shunt block: what are the best predictive clinical indicators? Arch Dis Child 2002;87(3):198-201

6 Watkins L, Hayward R, Andar U, Harkness W. The diagnosis of blocked cerebrospinal fluid shunts: a prospective study of referral to a paediatric neurosurgical unit. Childs Nerv Syst 1994;10(2):87-90

7 Chiewvit S, Nuntaaree S, Kanchaanapiboon P, Chiewvit P. Assessment lumboperitoneal or ventriculoperitoneal shunt patency by radionuclide technique: a review experience cases. World J Nucl Med 2014;13(2):75-84

8 Ejike JC, Bahjri K, Mathur M. What is the normal intra-abdominal pressure in critically ill children and how should we measure it? Crit Care Med 2008;36(7):2157-2162

9 Ouellette D, Lynch T, Bruder E, et al. Additive value of nuclear medicine shuntograms to computed tomography for suspected cerebrospinal fluid shunt obstruction in the pediatric emergency department. Pediatr Emerg Care 2009;25(12):827-830

10 Sood S, Canady AI, Ham SD. Evaluation of shunt malfunction using shunt site reservoir. Pediatr Neurosurg 2000;32(4):180-186

11 Piatt JH Jr. Pumping the shunt revisited. A longitudinal study. Pediatr Neurosurg 1996;25(2):73-76, discussion 76-77

12 Johna S, Taylor E, Brown C, Zimmerman G. Abdominal compartment syndrome: does intra-cystic pressure reflect actual intra-abdominal pressure? A prospective study in surgical patients. Crit Care 1999;3(6):135-138

13 Dunn LT. Raised intracranial pressure. J Neurol Neurosurg Psychiatry 2002;73(Suppl 1):i23-i27 